\title{
EL PROCESO ESQUIZOIDE A TRAVÉS DE LA MIRADA DE R. ERSKINE: "DIÁLOGOS Y REFLEXIONES"
}

\section{THE SCHIZOID PROCESS THROUGH R. ERSKINE'S REGARD: "DIALOGUES AND REFLECTIONS"}

\author{
Amaia Mauriz Etxabe \\ Bios Instituto de Psicoterapia Integrativa, Bilbao, Bizkaia, España \\ ORCID: https://orcid.org/0000-0003-2318-7421
}

Cómo referenciar este artículo/How to reference this article:

Mauriz-Etxabe, A. (2021). El proceso esquizoide a través de la mirada de R. Erskine: "Diálogos y reflexiones". Revista de Psicoterapia, 32(118), 59-80. https://doi.org/10.33898/rdp.v32i118.485

\section{Resumen}

El concepto de Proceso Esquizoide es uno de los más innovadores y complejos de la teoría y práctica de la Psicoterapia Integrativa. Fue desarrollado por el Dr. Erskine $(1999,2020)$ en su búsqueda por comprender las dificultades emocionales y las perturbaciones adaptativas desde una visión no patologizante. Ofrece una fórmula diagnóstica de los procesos psíquicos que resulta operativa para el tratamiento y el establecimiento del trabajo clínico y aporta una visión que permite acercarnos a la persona que a menudo vive, según palabras de Mary O’Reilly-Knapp (2017), en una "desesperanza tranquila" con una mirada de respeto y profundidad. Nos enseña a escuchar sus fases $y$, sobre todo, a escuchar las palabras no pronunciadas del silencio (O’Reilly-Knapp, 2001). Este artículo entrelazará extractos de las entrevistas con el Dr. Erskine con viñetas clínicas de mi propia experiencia para resaltar la importancia central de la posición interna de la mirada del o de la psicoterapeuta para el resultado de la psicoterapia.

Palabras Clave: psicoterapia integrativa, proceso

Correspondencia sobre este artículo:

E-mail: amaiamauriz@gmail.com derecha, 48008 Bilbao, España

(C) 2021 Revista de Psicoterapia

\begin{abstract}
The concept of Schizoid Process is one of the most complex and new concepts that Integrative Psychotherapy brings to the psychotherapy world. It was developed and described by R. Erskine (1999, 2020) in his way of comprehending and looking to the human being's emotional disturbances from a non-pathological point of view and also from his commitment on establishing a way of diagnosing the psychological processes in a useful way in terms of treatment plans and to organise the different stages of the clinical work. This concept gives us the opportunity to approximate at - what Mary O'Reilly-Knapp (2017) calls "the quiet despair"'-with a deep and respectful look. It teaches us to listen its different phases and above anything else, it teaches us how to listen the never verbalised words that are hidden inside the silence (O'Reilly-Knapp, 2001). In this article, we will approximate to this concept trough clinical segments from my own experience as psychotherapist, along with some extracts taken from a series of interviews made to Richard Erskine about the topic. We are going to show here the relevance of the psychotherapist way of looking to the client for the result of the psychotherapy.

Keywords: integrative psychotherapy, schizoid process, therapeutic relationship, relational methods, developmental stages
\end{abstract}

Fecha de recepción: 4 de octubre de 2020. Fecha de aceptación: 6 de noviembre de 2020.

Dirección postal: Bios Instituto de Psicoterapia Integrativa, Calle Bertendona $n^{\circ}$ 1, planta baja

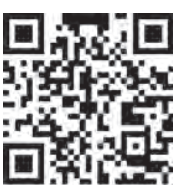


La Psicoterapia Integrativa Relacional está asentada en un amplio bagaje teórico que incluye aspectos centrales de la teoría Gestalt donde la coherencia de fondo y forma es significativa para la transmisión del mensaje a nivel de meta-comunicación; y tomando en consideración tanto el nivel explícito como implícito (Arnheim, 1972; Bateson, 1972/1976; Granit, 1977; Jaynes, 1977; Masters y Houston, 1972; Miller, 1975; Perls, 1942/1975), está también basada en los principios del aprendizaje experiencial (Kolb, 1984). Este artículo, en consecuencia y por razones de coherencia teórica, alternará el uso de la tercera persona con la primera persona del singular. Otro aspecto fundamental en Psicoterapia Integrativa se refiere a la consideración de la relación terapéutica como un espacio relacional co-creado e intersubjetivo donde ambas partes de la ecuación relacional deben tomar responsabilidad explícita en el proceso terapéutico (Guistolise, 1996; Moursund y Erskine, 2003; Yalom, 2001/2002). Se asienta, en definitiva, en una arraigada tradición de la psicología humanista donde el uso del propio self del psicoterapeuta es un aspecto troncal como un elemento central del proceso y donde el denominado "self-disclosure" (García-Monge, 2017; Gimeno-Bayón, 2017) o la apertura por parte del psicoterapeuta a mostrarse, es una herramienta esencial del proceso terapéutico. La implicación (Erskine et al., 1999) calibrada y con un objetivo clínico es por tanto un requisito de la acción en psicoterapia tal como puede verse en todo enfoque humanista en general y en la psicoterapia integrativa en particular. Este artículo por tanto respetará estos principios teóricos a través del uso complementario de la primera y la tercera persona del singular en la presentación de los casos y de los planteamientos teóricos expuestos.

El concepto de Proceso Esquizoide es un enfoque único y novedoso que aporta la Psicoterapia Integrativa y que fue desarrollado por el Dr. Erskine en la década de los 90. Resulta esencial para la comprensión y el tratamiento de diversos procesos psicológicos de difícil abordaje y está en la base de algunos desórdenes de la personalidad; está vinculado, además a la experiencia psíquica de la relación que muchas personas mantienen con el mundo que les rodea. La comprensión y tratamiento de los procesos psicológicos de esta índole ha venido abordándose durante años desde el concepto psicoanalítico de resistencia. Fenómenos que habitualmente han sido considerados como una expresión activa de intensos mecanismos de defensa primarios y arcaicos y que han sido catalogados desde un diagnóstico generalista englobado en el amplio paraguas de la depresión como entidad clínica.

Cuando en los años 90 comencé a acudir a los talleres de formación en Psicoterapia Integrativa que impartía el Dr. Erskine en Madrid, me impresionó lo operativo del enfoque para su aplicación a la práctica clínica y también la visión que ofrecía para la psicoterapia individual.

En aquel entonces yo tenía bastantes pacientes y el trabajo con varios de ellos conllevaba un desafío a las habilidades clínicas y métodos que yo había desarrollado en las diversas formaciones previas: el entrenamiento en métodos psiocodramáticos, nociones psicoanalíticas combinadas con una formación extensa en Análisis Tran- 
saccional: confrontar, interpretar, ilustrar, clarificar, plantear contratos de cambio, el uso de la introspección a través de diversos recursos, etc. En ocasiones, con algunos de estos clientes, la sensación era de estar comprometida con la búsqueda de nuevas formas de abordar lo que les ocurría, con encontrar nuevos métodos y una mirada clínica que asegurase un trabajo más profundo y eficaz para producir un cambio estable más allá de la mejoría que a menudo conseguíamos. Hoy es posible afirmar que lo que buscaba era la cura del guion de vida (Berne, 1966; Erskine, 1999; Perls, citado en Rosenfeld, 1978) y no el cambio y la mejoría.

En particular, recuerdo a una mujer joven, ingeniera de profesión, soltera, muy inteligente y motivada que acudió en busca de psicoterapia por recomendación de un colega que me conocía de algún encuentro profesional previo.

Susana entró en la consulta con una amable sonrisa, bien vestida y con un aire general de discreción que se mostraba tanto en su forma de vestir, como de hablar o incluso de moverse. Expresó su motivación para abordar la psicoterapia y comentó que le animaban dos objetivos fundamentales: el deseo de conocerse más y de "entender algunas cosas que hacía", así como de afrontar la ansiedad que "se disparaba de más y sin mucha lógica" en diversas situaciones.

Su forma de presentarse y su buena disposición para una psicoterapia seria me suscitaron interés y una reacción espontánea de simpatía.

Comenzamos las sesiones exploratorias y observé con extrañeza que nada de lo que relataba parecía poder explicar ni el origen ni el posible desencadenante de sus frecuentes reacciones de ansiedad, las cuales, a menudo, iban acompañadas de algunos síntomas digestivos y vasovagales. Estos consistían generalmente en algunas molestias estomacales y sensaciones de mareo, que fueron disminuyendo y que pronto remitieron ya en el periodo inicial de la terapia (Cornell, 2019; Damasio, 2010; Nathanson, 1987). Esto me hizo pensar en que quizás de alguna manera, la terapia regular le estaba ofreciendo un espacio seguro y que el hecho de poder volcar algunos de sus sentimientos, preocupaciones y temores ofrecía al menos un lugar válido donde poner en palabras parte de lo que estaba sintiendo y viviendo. Aunque aún no éramos capaces -ninguna de las dos- de ver el alcance de aquello que le despertaba ese tipo de reacciones ni su función.

Aun así, había otros síntomas que fue narrando más adelante y a los que Susana no había dado importancia al comienzo de la terapia y que "secuestraban” buena parte de su tiempo, su energía y su atención. Ese síntoma era una acción compulsiva y cotidiana que le llevaba a hacer listas y listas de tareas pendientes: listas de lo que ya había hecho, listas de lo que quedaba por hacer, etc. Esa tarea de las listas era diaria, de hecho, varias veces al día y restringía su posibilidad de salir con amigas, descansar o establecer otro uso de su tiempo. Ella lo llamaba "mis manías".

Cabía preguntarse si sería una resistencia que se expresaba a través de esta forma de comportamiento (Coderch, 1987/2016) o si, en cambio, Susana provenía de un entorno donde esas tareas compulsivas eran parte de la cultura familiar y de su marco de referencia. 
Yo no me sentía preparada para dar un sentido significativo a estas "manías" y tampoco podía aún ofrecer un plan de tratamiento mucho más allá de plantear propuestas de control del síntoma a través de contratos de cambio (Berne, 1961, 1966; Steiner, 1974/1991) y del establecimiento de alguna hipótesis y alguna interpretación, en principio, no muy atinada... Sabía cómo confrontar, cómo interpretar (Coderch, 1987/2016) pero no sabía cómo entrar en el escenario mental que, inevitablemente, conllevaban esas "manías".

En este contexto, comenzó mi formación en Psicoterapia Integrativa con el Dr. Erskine y recuerdo el alivio y la alegría que supuso ese primer taller donde habló de muchas cosas pero, sobre todo, vi cómo él escuchaba: escuchar... escuchar lo que se decía y escuchar lo que no se decía; escuchar también el silencio y acompañarlo, estar ahí, plenamente ahí con la persona sin tratar de cambiar nada... sólo escuchar y estar para la persona y con la persona. Me llevé conmigo el principio de la Psicoterapia Integrativa que afirma que todo lo que no tiene sentido en el hoy, tuvo sentido y fue relevante en algún momento de la vida de la persona. En definitiva, es un trozo de historia en acción; una parte de sus recuerdos en forma codificada, no un recuerdo explícito (Erskine y Mauriz, 2020).

Volví a mi siguiente sesión con Susana con la convicción de acompañarla y la determinación de tomarme el tiempo de escuchar la historia que estaba codificada en la acción y de ayudarle a poner en palabras lo que, de momento, era un trozo de historia pero de narrativa aún desconocida. Así empecé a indagar sobre sus sensaciones al hacer las listas, lo que ella experimentaba y a tener curiosidad por conocer todo lo relativo a su experiencia fenomenológica. Le pregunté qué sentía cuando hacía las listas y ¡entramos juntas en una experiencia fascinante!

Inicialmente Susana me dijo: "No sé, creo que no siento nada". Su voz se hizo más lenta, su mirada más lejana, como si de alguna manera me estuviese hablando desde un lugar distante. Escuché ese silencio, escuché ese cambio en el ritmo, empecé a hablarle más suave y más lento al mismo compás que ella, con largas pausas y pocos gestos.

Y así, poco a poco fuimos adentrándonos en sus recuerdos... en un tipo de recuerdos que no estaba hecho de palabras sino de sensaciones, de calmas y silencios que se construían al hacer listados y listados de tareas que le permitían encontrar una especie de mantra que le trasladaba a un espacio psíquico distante y calmo que, con el transcurrir del trabajo clínico, se reveló como la huella de un tiempo temprano donde en su familia había tanta tensión, conflicto y locura que solo una tarea reiterativa y sencilla podía acallar el efecto de lo que ocurría alrededor de una niña de ocho años.

En definitiva, tuvimos que poner nuestra atención -la de Susana y la mía-, en solamente escuchar, escuchar y escuchar hasta que la memoria inscrita en sus síntomas pudiese ir encontrando una narrativa más explícita. Ese fue, por muchos meses, nuestro trabajo: desentrañar las memorias de Susana representadas en aquel síntoma que, en realidad, había funcionado a modo de escondrijo donde una niña 
pudo retirarse cuando el conflicto externo y su propia soledad le llevaron a encontrar una fórmula creativa que le permitiese manejar la angustia que le provocaba su entorno en aquel periodo.

\section{La Mirada en Psicoterapia: Mirando al Escondrijo}

Fue entonces, en aquel taller, donde aprendí a trabajar con lo que más adelante el Dr. Erskine (1999; Erskine y Moursund, 2020) describiría como el proceso esquizoide y que tan relevante resultó para el proceso terapéutico de Susana.

Tomé conciencia de que, en realidad, a través de sus síntomas nos enfrentábamos a la aventura de descifrar su proceso inconsciente y abordar la cura del guion.

Trabajar con el sistema de guion de Susana implicaría tomar en cuenta que “el guion de vida” se mantiene activo en la vida actual de la persona. Más que tomar una perspectiva histórica, el sistema de guion "identifica cómo las decisiones, conclusiones, reacciones y/o introyecciones son expresadas de manera inconsciente en la vida actual de la persona en forma de creencias nucleares, conductas explícitas, fantasías, obsesiones, sensaciones físicas internas y memorias reforzantes” (Erskine, 2015/2016a, p. 114).

¡Sus síntomas serían, por tanto, una guía que nos llevaría a su guion y experiencia previa!

Erskine, en el mismo texto continúa describiendo:

Las dinámicas intrapsíquicas del sistema de guion sirven para mantener las necesidades originales y lo sentimientos que estuvieron presentes en el momento de la formación del guion fuera de la consciencia, al tiempo que permiten mantener una apariencia de vinculación con los otros. (Erskine, 2015/2016a; p. 114)

Probablemente, el trabajo terapéutico iba a desafiar esas funciones del guion y suscitar, sin duda, dificultades relacionales que se tendrían que sortear y resolver. Dificultades ante las que mi propia comprensión y mi mirada ante el proceso resultarían esenciales para poder convertirlas en un elemento más del trabajo del guion y que requeriría, por tanto, de buenas dosis de introspección propia, bastante supervisión y probablemente abandonar posiciones conocidas e interpretaciones. Por tanto, sería importante tener claro que:

Cualquier interpretación conlleva señalar patrones y aspectos relacionales que el cliente no ha identificado todavía [...] y uno de los más obvios peligros es que la interpretación puede no ser correcta, pero aún si lo es, la persona puede rechazarla y pensar que el terapeuta no le entiende. O si la acepta, lo haga obviando y no validando su propia percepción sobre su experiencia. En ambos casos, esto no ayuda al proceso terapéutico. (Moursund y Erskine, 2003, p. 95)

Era necesario el abordaje de un camino nuevo y cocreado. Citando una advertencia que el grupoanalista Bion hacía a los psicoanalistas que "acumulaban conocimiento”: “Cuanto más exitosa es la memoria en su acumulación, más cerca 
estará de parecer un elemento saturado de elementos saturados. Un analista con este tipo de mente es alguien que resultará incapaz de aprender porque ya está satisfecho" (Bion, 1967, p. 29). Y, por otro lado, hablando de las primeras sesiones, Berne (1966) dice que el terapeuta debe acudir cada día con una energía renovada, con curiosidad y dispuesto a aprender algo nuevo.

Así, el desafío sería recordar en todo momento que la conexión entre cliente y psicoterapeuta es la herramienta más importante de la que este último dispone y las intervenciones deben ser realizadas, principalmente, de tal forma que preserven y apoyen dicha relación. Algunas intervenciones demuestran ser útiles para ayudar a nuestros clientes a acceder y trabajar con creencias sobre sí y con sentimientos ocultos, pero se debe tener en cuenta que sólo resultan útiles en el contexto de la relación terapéutica en la que se producen (Mauriz, 2004; Moursund y Erskine, 2003). Ciertamente, tal y como establecen Moursund y Erskine (2003):

La relación aporta un impacto a la intervención que la hace creíble, que anima al cliente a utilizar su propia forma de experimentación con maneras nuevas de pensar y de sentir acerca de sí mismo y del mundo que le rodea. (p. 162)

Tener todo ello en cuenta resultó ser esencial para acompañar a Susana a resolver tanto la ansiedad como el miedo que la acompañaban de forma constante, tal y como fuimos desvelando pronto. También descubrimos que sus denominadas "manías" le aportaban una estrategia de manejo y distanciamiento emocional aprendida en la infancia para calmar la angustia profunda que para ella iba ligada a cualquier relación significativa.

Mi tarea iba a ser acercarme a aquello que parecía estar cargado de dolor, ayudarle y acompañarle a recordar lo que había vivido y que dio lugar a estas conductas y sentimientos tan automatizados y potentes.

Ayudarle a integrar su experiencia pasada en lugar de revivir codificadamente el drama original (Berne, 1961; Erskine y Mauriz, 2020; Freud, 1914/1930) y seguir sintiéndose limitada e indefensa, manteniendo creencias de que "la relación trae dolor", "querer a otra persona y tener intimidad es peligroso" y que "algo falla en mí”. Estas eran creencias que le prevenían de cualquier relación de intimidad real más allá de amistades para practicar algún deporte o "salir de copas de vez en cuando".

Si queríamos hacer una terapia seria habría que construir una relación de confianza y por mi parte, acompañarle con humildad, profundo respeto y sintonía con su ritmo y su estilo personal... algo que en su casa nunca existió puesto que solo la exigencia constante y el exceso de responsabilidad temprana habían tenido cabida en el estilo de parentalización recibida, junto con la negación de su experiencia de agresión y actitudes de locura y violencia por parte de su padre que siempre fueron negadas en la familia.

Me dispuse a escuchar la sensación de silencio interno que Susana describía sentir al hacer listas y listas de tareas, a acompañarle a experimentarlo y a descubrir qué puertas abría a su memoria. 
En una sesión Susana relató:

SUSANA: Ayer domingo fui a comer a la casa de mis padres.

A: Humm...(asintiendo) ¿sueles ir los domingos?

SUSANA: Sí, siempre me cuesta, esa casa me da una sensación de oscuridad.

A: ¿Oscuridad? Te había oído comentar que tus padres tienen una casa preciosa.

SUSANA: Y lo es... Soy yo que lo siento oscuro.

A: Humm, humm (asintiendo lentamente, como alentándole a proseguir). SUSANA: (su voz se va haciendo más lenta, su respiración más pesada) No sé... No sé... (con una mirada distante, como si estuviese en otro lugar). A: (respirando a su ritmo, en silencio por un rato) Estoy aquí contigo... Tómate tu tiempo Susana.

SUSANA: (con la respiración más pesada, el silencio más denso) Es como... Es como... Oscuro...

A: (con voz muy suave y lenta): Hummm, hummm (asintiendo para acompañar y validar la relevancia de la experiencia que comenzaba a desgranar). Estoy aquí Susana, no hay prisa.

SUSANA: (de nuevo en silencio por un largo tiempo) Es como... Como... Adormecerse... Como que todo se para.

A: Hummm, hummm... Quizás es una sensación que ya conoces... quizás es una sensación que experimentabas en algún lugar...

SUSANA: (pausa muy larga, cierra espontáneamente los ojos, la respiración aún más lenta).

A: (respira en silencio y de vez en cuando dice "hummm, hummm” para que Susana recuerde, sienta que no está sola con sus recuerdos).

De pronto, cae una lágrima lenta por su rostro.

A: Susana, debe de ser doloroso. Estoy aquí contigo. No estás sola.

SUSANA: Estoy en mi habitación, en la que dormía cuando tenía 7 años. Mis padres han discutido en el salón y luego mi padre se ha puesto a chillar... Yo creo que va a pegar a mi madre... Le oigo pegar a la pared... Estoy aterrorizada... Mi hermano es tan pequeño; está en la cuna y mamá llora... No me puedo mover...

A: Sigue, puedes contarme lo que ves... (Susana tiembla, el gesto es como un escalofrío). Estoy aquí contigo y nada malo te va a ocurrir. (Suavemente) Puedes recordar; puedes contármelo.

SUSANA: (se queda de nuevo muy quieta, en silencio por un largo tiempo) No quiero oír, no quiero... Luego me dirán... Como siempre... Que no ha pasado nada... (con voz muy suave, hablando muy, muy bajo).

A: ¿Dicen que no ha pasado nada?

SUSANA: Sílíí. Si pregunto a mamá dice que estaban charlando, que no ha pasado nada. (Su voz cambia, como si estuviese enfadada pero aún muy bajito). 
A: Y... ¿qué ocurre entonces en ti? (hablando suave también).

SUSANA: Naadaaa... Me vuelvo a mi cuarto.

A: ¿Y qué sientes?

SUSANA: Naaadaaa (con largos silencios y pausas intercaladas).

A: ¿Nada?... ¿Y qué haces en tu cuarto?

SUSANA: Lo que me ha mandado papá.

A: ¿Lo que te ha mandado papá? (pausa).

SUSANA: Síííl. Que me ponga a escribir.

Posteriormente, tras varias sesiones en las que hubo largas pausas y silencios, finalmente apareció el recuerdo de una Susana de siete años que refugiada en su habitación, intenta escribir, hacer las tareas escolares y no logra concentrarse pero descubre la calma de escribir las tareas, concentrarse en la caligrafía y repetir, repetir y repetir lo que escribe como un refugio de la soledad y el miedo, y que le ofrece una especie de muralla donde, si está escribiendo, nadie (papá) se meterá con ella ni tampoco notará su sensación profunda de desamparo y soledad.

Estas sesiones, seguidas por tiempos de silencio, sirvieron para que ella pudiera decirme qué significaban para ella esos recuerdos, para tomarnos tiempo en apreciar lo importante que había sido para estabilizarse, para poder regular todo lo que estaba viviendo, para entender la gran confusión que esa niña sentía -con un papá estupendo a veces y que se convertía en un loco violento otras- y no tenía con quién compartir. De esta forma, sólo adormecerse haciendo una tarea rutinaria podía ofrecerle un tipo de calma que resultaba de ayuda y regulación, en la ausencia de adultos que protegiesen, explicasen y reparasen el efecto del trauma que toda esa situación conllevaba.

\section{Recordar para no Revivir: Reorganizando la Experiencia Recordada}

En psicoterapia siempre se pone atención en los procesos relativos a la memoria: ¿Cómo aparecen las memorias en la mente de la persona? ¿Cómo son? $¿$ ¿Son recuerdos que resultan de ayuda o son memorias intrusivas en la vida actual de la persona?

$\dot{¿}$ Son recuerdos que aparecen de una forma constructiva? $\mathrm{O} \dot{\mathrm{c}}$ son las huellas, una forma de reminiscencia del trauma o la negligencia que la persona experimentó en el pasado? Y si ese es el caso, ¿acaso son recuerdos que se utilizan para fortalecer la resiliencia o aparecen en las reacciones de la persona como una especie de sombra que no le permite ver el aquí y el ahora sin la contaminación de los afectos, de los sentimientos, las conclusiones y las fórmulas procedimentales que había desarrollado en el pasado para manejarse con aquel trauma?

En resumen, a menudo, estas memorias no aparecen en forma de imágenes o pensamientos ni en ninguna otra forma de recuerdos explícitos y en ellas, el trauma antiguo suele manifestarse "mucho más allá de las palabras" (Lanyado y Horne, 2009, p. 307).

Estas memorias aparecen con mayor frecuencia en forma de sentimientos, 
comportamientos estereotipados o respuestas automáticas, gestos o incluso sensaciones vagas pero que ejercen una intensa influencia en los patrones reactivos de la persona ante el mundo (Erskine, 2015/2016a; Siegel, 1999; Van der Kolk et al., 2007).

Este tipo de recuerdos y memorias son importantes en el curso de un proceso real de psicoterapia porque tienen una gran influencia en la forma en que la persona percibe y se relaciona con su entorno y también consigo misma; asimismo, tienen una gran influencia en las decisiones que toma y en el manejo de su salud, su autonomía y sus actitudes ante todo tipo de eventos y vínculos (Berne, 1961; Erskine, 2010, 2015/2016a; Van Der Kolk et al., 2007).

Dado que en la mayor parte de los casos estamos hablando de diversos tipos de memoria implícita, lo probable es que la persona no lo describa como recuerdo o memoria, sino que lo describa como síntomas, reacciones inapropiadas, "inundaciones" emocionales o que incluso sean los miembros de la familia los que requieran que se resuelvan al verlos como conductas o reacciones inadecuadas; cuando lo que en realidad representan es una parte de su pasado, una huella concreta de su historia.

La cuestión relevante es entonces cómo ayudar a la persona a que

- Adquiera consciencia del proceso real que está expresándose de forma no obvia;

- pueda apropiarse de dichas reacciones;

- comprenda su significado;

- pueda elaborar los sentimientos y emociones no resueltos;

- pueda elaborar las necesidades relacionales no satisfechas y que por lo tanto, resultaron fijadas; y deseablemente;

- pueda integrar todo ello en su personalidad y contexto actual.

Esto es, por supuesto, un proceso que debe producirse más allá de la mera comprensión cognitiva, más bien debe tratarse de una especie de "metabolización" de aquello que ocurrió, de lo que debió de haber ocurrido pero no pasó, y de los efectos que aquellas experiencias dejaron en la persona y en su percepción del mundo que le rodea.

Diferentes autores proponen formas varias de trabajar a través de todo ello en función del marco de referencia teórico que representan. Aun así, es obvio que comparten la idea de la relevancia de observar y comprender el proceso de formación y actuación de dichas memorias y por supuesto, del trauma no resuelto que subyace a ellas.

De este modo, los psicoanalistas, por ejemplo, suelen proponer que se facilite la toma de conciencia y la comprensión de la historia subyacente, sus significados y la comprensión de la forma en que la persona manejó todo ello, así como de los consecuentes mecanismos de defensa que se articularon en torno a lo vivido (Bronstein, citado en McGinley y Varchevker, 2013; Erskine, 2016b. Por otra parte, los terapeutas cognitivo-conductuales suelen proponer un control de las reacciones, la comprensión de las funciones y orientarse hacia el cambio en acción, tanto de 
la conducta como de las variables intervinientes, de tal forma que un cambio de acción finalmente propulse un cambio de la mente (Bravo, 2019; Echeburúa, 2019).

Los psicoterapeutas de la Gestalt ponen su atención en los afectos ligados a estas memorias, en el manejo activo y emocional del conflicto psíquico emergente y en las diversas formas de trabajar activamente con las emociones no integradas y las decisiones arcaicas (Perls, 1942/1975; Perls et al., 1977).

En esta misma dirección, el Análisis Transaccional pondría el foco en trabajar con contratos de cambio, identificar y comprender los mandatos parentales inconscientes que estén en la base de todo ello y en identificar y trabajar las decisiones tempranas (Berne, 1961, 1966; MacNeil, 1985; Steiner, 1974/1991).

Desde la perspectiva de la Psicoterapia Integrativa, la tarea implica tomar en consideración todos estos métodos de abordaje previamente citados pero poniendo el énfasis en la centralidad de la relación terapéutica y en la importancia de abordar el significado y contenido emocional de estas memorias en diferentes etapas, teniendo siempre en cuenta los niveles evolutivos y los periodos en los que se produjo el trauma. De esta forma, la psicoterapia se convierte en un proceso intersubjetivo e implicado, sintónico y dinámico que se va ajustando a los diferentes Estados del Yo donde se produjo la "huella psíquica" tan relevante que aún da forma a la vida de la persona en el presente (Erskine y Moursund, 1988/2014; Erskine et al., 1999).

En definitiva, cabe subrayar que, en un proceso profundo, lo que la Psicoterapia Integrativa propone es:

- Ayudar a la persona a crear una narrativa que sea significativa y que le facilite poder comprender qué es lo que está sucediendo en su mundo interior y de qué manera esto se manifiesta a nivel externo.

- Ayudar a la persona a darse cuenta y a aceptar las diferentes formas en las cuales se expresan las memorias, así como a acompañarle a tolerar el arousal de afectos que se está produciendo en este proceso de "revivir" como forma de expresar los recuerdos (de manera tal que reacciones bizarras y desproporcionadas tienden a disminuir e integrarse, bien por efecto del trabajo terapéutico activo, o bien por la presencia sólida e implicada de la psicoterapeuta).

- Identificar los significados que acompañan a estas memorias y ayudar a la persona a "darles la bienvenida" con el acompañamiento y el apoyo del psicoterapeuta en lugar de justificarlos, negarlos o actuarlos; de tal forma que pueda abrirse a nuevos y más actualizados significados acordes al aquí y ahora real de la persona.

- Identificar las necesidades relacionales reprimidas, aquellas que no resultaron satisfechas en el tiempo en que se produjo la represión y la consecuente fijación.

Y, de esta manera, ayudar a la persona a identificarlas, aceptarlas y a hacer el duelo de lo que hubiese debido ocurrir pero no ocurrió. Deseablemente, a continuación, acompañarle a tomar el riesgo de explorar nuevas formas 
de expresar sus necesidades relacionales, utilizando inicialmente el propio marco de la relación terapéutica individual y/o grupal como laboratorio relacional seguro, donde se pueda experimentar un encuentro intersubjetivo nuevo para simultánea y progresivamente llevar esta nueva fórmula al mundo exterior (Erskine y Moursund, 2020).

- Comprender las funciones que esta repetición de recuerdos en forma de reacciones pueda estar cumpliendo y encontrar formas nuevas más allá de la compulsión de repetición (Erskine y Mauriz, 2020; Freud, 1914/1930).

- Expresar y experimentar con los afectos desapropiados y negados, sentimientos y afectos vinculados a la escena original, ayudando así a la persona a sentir lo que siente, identificando la experiencia interna reprimida y reconociendo sin miedo la necesaria externalización a través de gestos, protestas o expresiones que fueron bloqueadas y prohibidas y que representan aspectos negados o incluso disociados de la personalidad. En definitiva, trabajar en los diferentes Estados del Yo que hayan resultado reprimidos (Berne, 1961; Erskine et al., 1999) con el objetivo de facilitar que la persona pueda integrar lo vivido más allá de las palabras y procesarlo en un nivel experiencial.

Todo ello implica estar ahí con la persona y acompañarle a enfrentarse con los diferentes recuerdos, con las diferentes emociones y con los diferentes Estados del Yo que vaya a traer a la psicoterapia. Significa estar dispuestos a inferir la historia que hay tras cada transacción transferencial y a manejar nuestra propia contratransferencia como un instrumento para indagar histórica y fenomenológicamente, incluso para abrir un proceso de indagación basado en el uso de la inferencia que nos permita ir creando un mapa impresionista (Erskine y Mauriz, 2020) cada vez más detallado a través de las diferentes etapas de la relación psicoterapéutica. Esto implica estar ahí para la persona y sintonizar con las necesidades y estilos cognitivos de los diferentes Estados del Yo (Erskine y Moursund, 1988/2014), cada uno de ellos constituido por una miríada de experiencias traumáticas acumuladas de diversa índole (Bronstein, citado en McGinley y Varchevker, 2013).

El resultado de este proceso será una capacidad de enfocar la vida con una energía nueva ya que, previamente, una parte de la energía de la persona estaba ocupada en la represión de sentimientos, de recuerdos, necesidades, represión de Estados del Yo arcaicos pero aún activos o incluso introyecciones reguladoras (Erskine y Moursund, 1988/2014) y toda esa energía quedará ahora a disposición de la persona para sus objetivos actuales y su presente (Berne, 1961). La cura de las conclusiones y fijaciones arcaicas será experimentada como libertad para pensar, libertad para decidir, y libertad para relacionarse con otros y con la vida cotidiana de formas nuevas y más saludables (Erskine y Moursund, 1988/2014).

Para alcanzar con éxito los objetivos antes descritos, será necesario un variado repertorio de métodos, en particular, será central el uso de los métodos relacionales:

- La indagación, para que la persona pueda saber lo que sabe, para que 
sea capaz de reconocer lo que siente, se atreva a identificar y aceptar sus necesidades. Una indagación que le permita identificar sus recuerdos y apropiarse de sus fantasías y de sus sueños; una indagación que le permita ver el significado y la relevancia afectiva de lo vivido y reconocer el valor de su propia vulnerabilidad; una indagación que le permita descubrir las formas de autoprotección que una vez desarrolló para cubrir su vulnerabilidad y... tantos otros descubrimientos que la persona puede encontrar en el camino de la psicoterapia a través de una indagación fenomenológica e histórica bien enfocada.

- La sintonía que facilita que la persona obtenga el soporte, la guía y el acompañamiento para que pueda, en definitiva, comenzar a sintonizar consigo misma: con sus necesidades, con sus reacciones evolutivas fijadas y con sus estilos cognitivos y afectos propios. Incluso para poder sintonizarse con su propio ritmo personal, el cual, a menudo, se pierde en el intento de la niña o el niño de adaptarse a los requisitos del entorno y muy especialmente a los requisitos parentales.

- La implicación, la única manera a través de la cual la persona puede afrontar todo este camino sin la soledad que lo convertiría en un proceso retraumatizante; la única fórmula con la que la aceptación puede oponerse a la intensa crítica interna que, a menudo, acompaña a la persona. La implicación es la base donde la persona puede apoyarse para enfrentarse a saber lo que sabe, reconocer lo que siente o que le permite recordar lo que constituyó la experiencia interna real.

La potencia de estos métodos relacionales (indagación, sintonía e implicación) puede verse en el caso de una cliente con la que trabajé años atrás; juntas abordamos el desafío de identificar y reconocer las necesidades más primarias de una niña que muy pronto tuvo que vivir rápido y eficazmente en un mundo dirigido por un padre impaciente, expeditivo y sobreexigente. Una niña que olvidaba ir al baño, que olvidaba comer y que olvidaba descansar... Una adulta que acudió a psicoterapia por recomendación de su médico que le dijo "que si no hacía terapia, el pronóstico era la enfermedad puesto que nunca paraba en sus tareas hasta que el dolor o el agotamiento extremo no la hiciesen parar”. Una niña que desde muy pequeña aprendió a responder a un papá que preguntaba diariamente: “¿Cómo tiene que ser mi niña?” y ella respondía, invariablemente para satisfacer a su padre: “¡Como una vela papá, como una vela!”.

Igualmente, parte de lo que me motivó a escribir este texto es el recuerdo de otro caso, el caso de Isabel. Una mujer que vino a mi consulta solicitando terapia y que cuando trató de empezar a narrar su historia, quedó muda, se quedó “en blanco” y decía no recordar y no poder hablar. Más adelante, en la terapia, cuando le pregunté por el silencio sostenido de las primeras sesiones a pesar de estar muy claramente motivada para el proceso terapéutico, Isabel me dijo: "de pronto era imposible hablar, era como si al contar los recuerdos que me atenazaban, de repente, 
todo lo ocurrido fuese más terrible y peor. Ya no podía contarlo, me fallaban las fuerzas incluso para oírlo yo misma”.

Sí, los métodos relacionales son instrumentos poderosos pero, a menudo, cuando la persona -como en el caso de Isabel- queda en el silencio o en el bloqueo, cuando la persona dice que no recuerda nada pero que sólo sabe que se encuentra mal, deprimida o profundamente estancada, entonces además de estos métodos relacionales podemos necesitar establecer hipótesis, construir preguntas y plantear intervenciones para atravesar procesos intrapsíquicos de difícil comprensión, procesos que necesitan "mapas líquidos", flexibles y que se construyen en base a la inferencia de lo que pudo haber ocurrido, de lo que esos gestos, esos bloqueos, ese silencio o ese "quedarse en blanco" puede estar comunicándonos. Lo que cuenta aquello que no ocurre, lo que cuenta aquello en que no se piensa y abordar así, con un proceso inferencial el mapa impresionista de lo que pudo haber ocurrido. La inferencia es un instrumento necesario allá donde no tengamos mapas -ni cliente, ni psicoterapeuta- para extrapolar lo que pudo haber ocurrido y guiar así nuestra indagación (Erskine, 1999; Erskine y Moursund, 2020).

Erskine define la inferencia cómo una "habilidad terapéutica relevante que resulta necesaria en varias formas de trabajo con los Estados Niños del Yo" y afirma que "nuestra indagación histórica está constantemente enfocada a trabajar hacia atrás en el tiempo" (Erskine, 2016b, p. 139). Dice, además que:

A menudo, comenzamos con preguntas acerca del periodo de la adolescencia, después seguimos con los años de la escuela. A menudo entrelazamos nuestra indagación histórica con indagación fenomenológica y con indagaciones acerca de cómo el cliente manejó aquellas situaciones. Para cuando llega el momento de preguntar sobre los años preescolares, posiblemente el cliente responderá "No lo sé" o "No lo recuerdo". Entonces les pedimos que imaginen su experiencia y que hagan una historia impresionista, dado que ellos ya conocen la personalidad de aquellos que eran significativos y cómo hubiesen respondido en tales situaciones. Estamos siempre trabajando con sensaciones, fragmentos de imágenes, impresiones e historias familiares, a todo lo cual llamamos "inferencia terapéutica". Es como si estuviésemos co-creando un collage de narrativa acerca de la historia de vida de nuestro cliente. (Erskine, 2016b, p. 143)

La inferencia, por tanto, se describe como un método que aplica el o la psicoterapeuta para profundizar en las vivencias y recuerdos de sus clientes. Pero lo que yo aprendí en aquellos primeros talleres con el Dr. Erskine es que tanto la capacidad de indagar como la inferencia terapéutica tienen su base en la experiencia interna del psicoterapeuta, en su curiosidad por conocer realmente a su cliente. Para ello, dejaremos de lado la interpretación convirtiéndola en una serie de indagaciones. En este sentido, la inferencia terapéutica comienza en el cuestionamiento interno que los psicoterapeutas nos hacemos cuando tratamos de imaginar el mundo en que nuestro cliente creció, las escenas que vivió, el estilo de cuidados que recibió, 
etc. (Moursund y Erskine, 2003). Esta inferencia tiene sentido cuando dejamos que nuestra imaginación e intuición nos guíen, materializándola en preguntas cuyo objetivo no es encontrar respuestas sino ayudar a la persona a imaginarse, a descubrirse y a recordarse desde un ángulo nuevo y más revelador.

Las preguntas que yo planteaba al escuchar a Isabel sobre su imposibilidad de hablar eran tales como: "Debe de ser muy atemorizante lo que estabas viendo" o "debía de haber mucho caos en tu familia cuando eras niña”; a lo que Isabel con los ojos anegados en lágrimas respondía: “sí, mamá bebía y papá también; muchas noches terminaban golpeándose pero... no sé si lo soñé porque por la mañana todo estaba en calma, parecía no haber ocurrido nunca".

Cuando le dije con empatía: "Debe de ser difícil recordar todo esto...”, Isabel respondió:

ISABEL: ¡Hace tanto tiempo...! Ahora se llevan bien y nadie habla de aquel tiempo... A veces pienso que quizás estoy exagerando.

A: ¿Podías hablar con alguien de lo que estaba ocurriendo?

ISABEL: No había nadie más en la casa. Yo era hija única y recuerdo que algunas veces cuando les pregunté por las peleas, se enfadaron y me instaron a no decir más tonterías. Decidí olvidar y no pensar más en ello... Quizás eran cosas mías...

ISABEL: (continuó) En adelante, cuando oía ruidos fuera, yo me iba adentro, a un lugar lejano y cantaba, cantaba y cantaba en mi mente para mecerme y poder dormir.

Quizás algunas personas se preguntarán, ¿por qué retraerse al dolor, a esos recuerdos tan difíciles...? La respuesta es sencilla: las estrategias de afrontamiento de entonces, a menudo se activan en el hoy; y así, Isabel tiene muchas quejas de su marido porque, cuando algo le duele o no le gusta, aún hoy, se pone a tararear y esta conducta, en la actualidad, está siendo motivo de conflictos de pareja y quejas laborales.

Isabel se distancia, se va a su mundo y se calma con formas arcaicas y se aleja del hoy y de los recursos que la mujer que es en la actualidad tiene. Es nuestra tarea juntas, convertir esas canciones y ese tarareo en emociones y en las frases que necesitó decir, hablar de las conversaciones que necesitó mantener; pero, antes de nada, ella misma debe poder escuchar la historia que su silencio guarda. Mi tarea es acompañarle a construir esa narrativa para que en lugar de revivir el trauma podamos enfrentarnos a recordar. Inevitablemente, tendremos que trabajar con métodos activos tales como dejar que la canción que hay tras el silencio se exprese, que se pueda mecer si eso es el gesto que inició, que pueda decir "tengo miedo" o lo que sea que aquella niña sentía y no pudo expresar... Mi tarea es facilitar que todas esas acciones amagadas en ese tararear puedan llevarse a cabo y así, cerrar la Gestalt incompleta (Erskine, 2015/2016a; Perls, 1942/1975; Perls et al., 1977;) para que la vivencia fijada tenga un cierre diferente y reparador (Erskine, 2015/2016a; Mauriz-Etxabe, 2004, 2016; Moreno, 1946/1974). 
En definitiva, diferentes personas con diferentes historias han encontrado una solución creativa a su dolor, su miedo y su angustia en un proceso de retirada interna y en ocultar su propio self vital y natural y necesitan ayuda para recordar y no revivir, para reorganizar la experiencia recordada.

\section{Retazos de una Conversación:}

\section{EI Proceso Esquizoide a través de la Mirada de Richard Erskine}

El enfoque y aprendizaje con Richard Erskine ha sido y es determinante en mi forma de abordar hoy estos procesos de retirada esquizoide. En mayo y junio de 2020, realizamos una serie de conversaciones sobre el abordaje del trabajo esquizoide en las que habla de diversos aspectos que cubren tanto sus primeras aproximaciones al tema, como su experiencia interna, sus dilemas clínicos e influencias de autores previos.

En la entrevista que expongo a continuación, el Dr. Erskine ofrece una perspectiva menos centrada en un objetivo teórico y afirma que su objetivo reside en tratar de ofrecer una descripción basada en la experiencia y en las palabras del cliente más que en adaptarse a una perspectiva teórica.

Se presenta aquí una pequeña parte transcrita de estas conversaciones con Richard Erskine, la cual puede ilustrar su posición y filosofía de trabajo en este complejo tema:

A: ¿Qué recuerdas de los inicios de tu trabajo con el proceso esquizoide? RICHARD: No había visto a nadie trabajar con este tema, pero mi propio psicoanalista era muy respetuoso con mis momentos de retirada y de silencio y eso me ofreció un cierto modelo. Al mismo tiempo, yo estaba experimentando todo ello con diferentes clientes que me hablaban de "ir a un lugar escondido" y de tener que hacer una retirada esquizoide para manejar el intenso miedo, la crítica interna o incluso una profunda vergüenza. Mi entrenamiento en la terapia centrada en la persona de Carl Rogers, en escuchar muy cuidadosamente, fue importante. Pero hubo largo proceso de experimentación con diversos clientes.

A: ¿Cómo encontrabas el ritmo para escuchar a la persona suficientemente para respetar su ritmo y al mismo tiempo mostrarte suficientemente presente y saber cuándo ayudar con alguna inferencia de modo que la persona no se sintiese de nuevo sola en el proceso?

RICHARD: Déjame leer una nota que yo usaba como guía. En ella digo "cuando tengo la impresión de que la persona se asusta, me digo: aunque no puedo observar directamente el aumento de la adrenalina o si se dispara el cortisol, puedo observar nuevos cambios en los gestos, cambios en la dilatación de las pupilas, cambios en la tensión de varios músculos de la mandíbula o de los hombros. Eso me dice que estoy yendo demasiado rápido y que debo crear una pausa”. Una pausa que está guiada por estos signos corporales y es paradójico, pero tengo que estar totalmente 
presente y simultáneamente no estar completamente presente para que mi ritmo no sea excesivo tal como lo describe Henry Guntrip en su libro "El compromiso esquizoide”.

A: ¿Cuándo fue la presentación inicial sobre este tema?

RICHARD: En 1999, presenté este tema en un simposio con otros colegas y lo que compartí fue en primer lugar mi intento de ser eficaz con este tipo de clientes.

Me había dado cuenta con un primer paciente de que, si en lugar de tratar de cambiarlo, lo escuchaba, tomaba en serio su retirada e incluso le animaba a descubrir cuál era su experiencia, resultaba de mucha mayor utilidad. Lo fui explorando con otros clientes y demostró ser una fórmula muy valiosa. Me encontré con un problema porque hay una parte simple en el proceso esquizoide que consiste en esta división entre la parte retirada y la parte social, entre el self vital (figura 1) y natural y la máscara (figura 2) que tendrá que ir desarrollando.

Figura 1. El self vital (Erskine, 2017b), ilustración (Landa, 2020a)

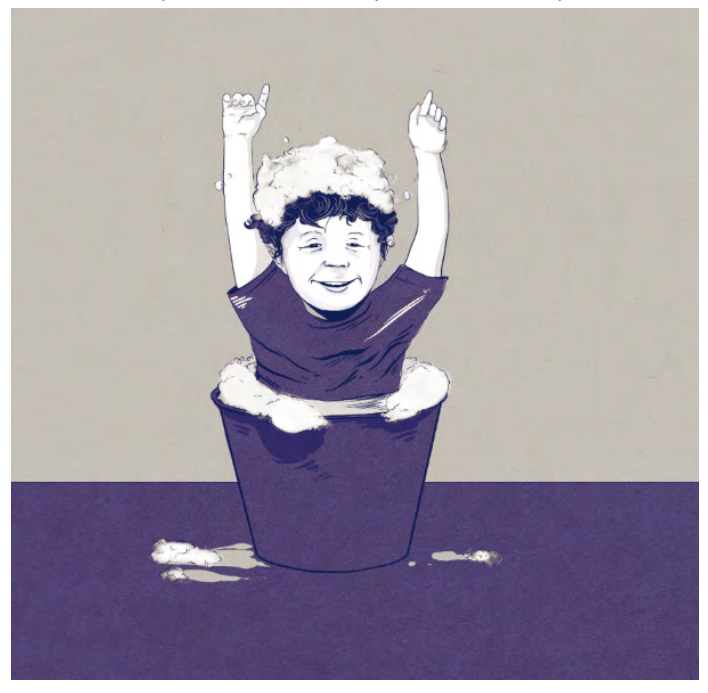

Este self natural y espontáneo es el que se va retirando y se esconde a causa del miedo.

Por otra parte, desarrolla una máscara social que está ahí porque está necesitando alguna conexión, aunque esa conexión en realidad no satisface al self natural porque está escondido. 
Figura 2. Primera ruptura: la máscara social o el falso self (Erskine, 2017b), ilustración (Landa, 2020b)

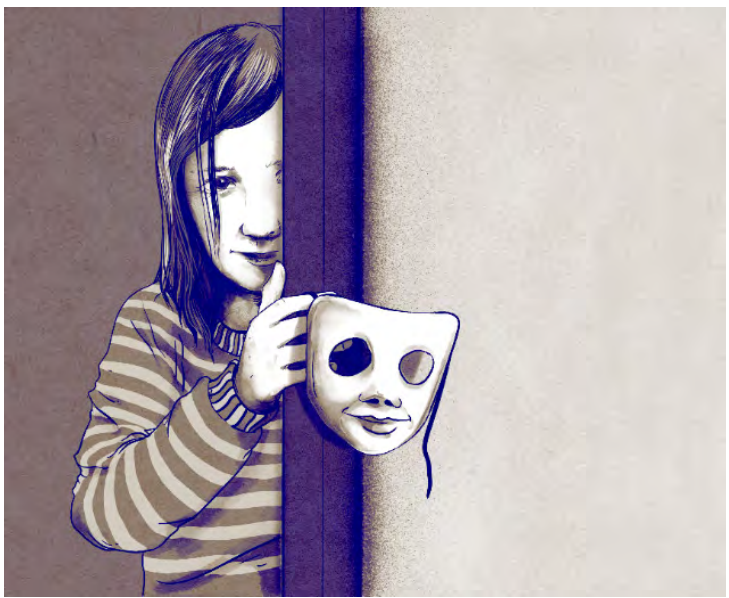

Luego empecé a observar otras dinámicas, tales como la dinámica de la crítica interna (figura 3).

Figura 3. Segunda ruptura: crítica introyectada(Erskine, 2017b), ilustración (Landa, 2020c)

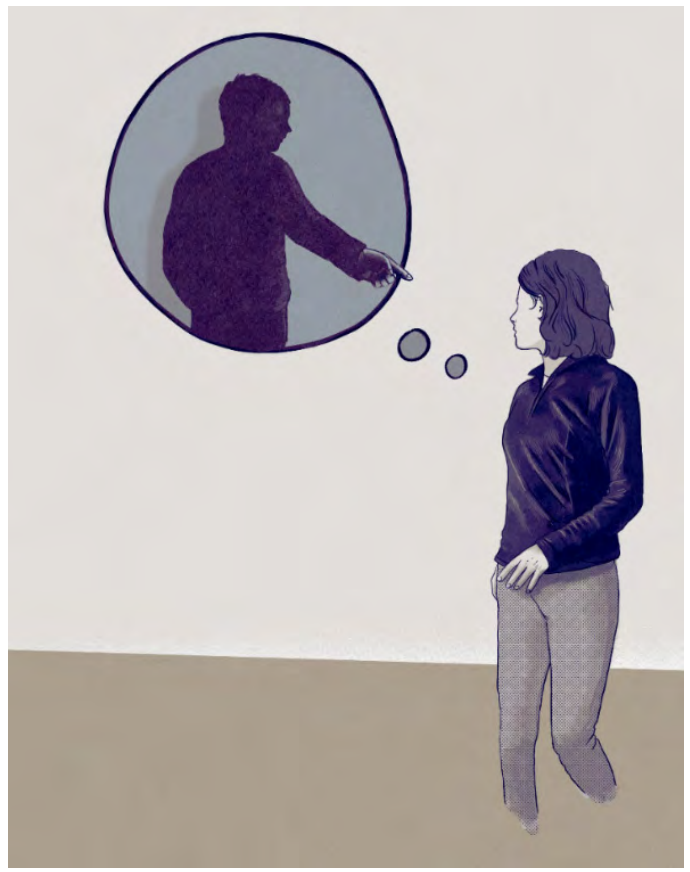

Me di cuenta de que algo que mantiene a mucha gente en esa retirada es 
la crítica interna (figura 4) la cual anticipa la crítica externa potencial. Así: si me critico yo primero, ¡tú ya no tendrás la posibilidad de criticarme! Por tanto, está la introyección como una fórmula autoprotectora.

Figura 4. Tercera ruptura: crítica autogenerada (Erskine, 2017b), ilustración (Landa, 2020d)

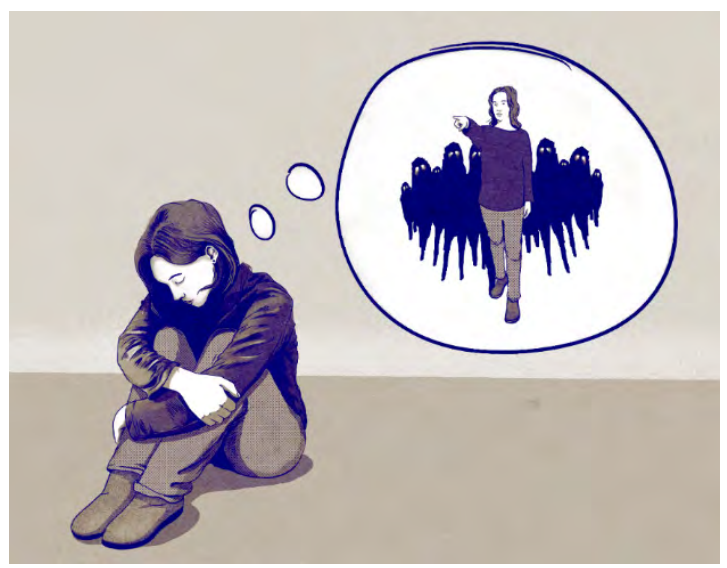

La crítica interna autogenerada viene después y tiene de alguna forma el objetivo de disminuir el efecto de las voces introyectadas. Así, si me critico duramente, ¡esas voces ya no tienen tanto efecto!

Y después se produce la retirada esquizoide: me escondo y así no estoy tan controlado por la introyección y no estoy en peligro (figura 5).

Figura 5. Retirada esquizoide (Erskine, 2017b), ilustración (Landa, 2020e)

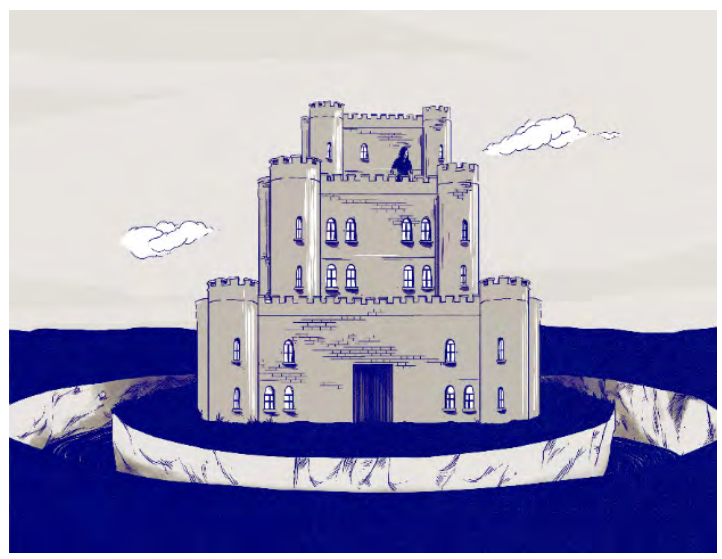

Así cada una de estas dinámicas corresponde a partes de la persona y hay que trabajar sobre ellas.

El proceso esquizoide es bastante complejo; me encantaría que fuese más 
sencillo para poder escribir mejor sobre ello... porque son dinámicas tan comunes a tantas personas en diferentes grados y modos que... ¿ ¿cómo escribir sobre el proceso esquizoide sin escribir sobre la gente en general? ¡Lo que es significativo en el proceso esquizoide es que la persona desatiende aspectos de su personalidad!

En 1992, Henry Yontef, Alan Jacobs, Ray Little, Mary O’Reilly y yo presentamos este tema en un congreso de Análisis Transaccional abordándolo desde diferentes perspectivas.

A: ¿Qué es lo que te parece más importante y especifico desde tu forma de trabajar con estas dinámicas?

RICHARD: Yo espero acercarme más desdela experiencia fenomenológica del cliente que desde la teoría. Realmente escuchar las palabras del cliente, su descripción fenomenológica y no tanto hacer interpretaciones desde una perspectiva teórica. Una de las cosas que dicen tantos clientes es lo importante que es el mantenerse presente, el estar ahí, relajado, plenamente presente acerca de crear un tono de voz que sea tranquilizador y que esté plenamente ahí observando lo que pasa de manera plena, sin tratar de hacer que pase nada. Tantos clientes dicen lo importante que es dejar a un lado mi deseo de que pase algo y observar lo que sí pasa; monitorizarme a mí mismo y preguntarme... "¿es mi conducta controladora? o ¿es invasiva de alguna manera?”.

Pero cuando estoy trabajando con la crítica interna es diferente: tengo que ir a por ella. La crítica interna está escondida a menudo por efecto de la vergüenza y hay que preguntar y buscarla. La persona puede que me diga: “sí, yo me critico a mí misma” y ya está. Así que tengo que decirle “¿qué quiere decir que te criticas?, dame un ejemplo". Y responde: "bueeenooo... ya sabes, me rebajo”. Y le digo: “venga, ¿qué te dices?” o “quiero conocer el tono o la velocidad". En definitiva, quiero que esa crítica interna se externalice, que se conozca su intensidad y finalmente, quiero escuchar esa voz interna e incluso implicarme en un diálogo con ella, eventualmente y más adelante, conocer su función. A menudo, esa voz ha tenido una función protectora que le ha protegido de recordar humillaciones o fallos o lo que fuese. Pero a menudo tiene tantos años de funcionamiento que el propósito se ha olvidado ya y se ha convertido en algo dañino. Querré saber también si es una voz autocreada o es la reminiscencia de figuras que despreciaban o desatendían al niño o niña que el cliente fue una vez. El abordaje de esos Estados del Yo introyectados será otra parte del trabajo; hacer terapia con esos Estados del Yo, que Berne denominó Estados del Yo excluidos.

En resumen, tras estas reflexiones de Erskine, vemos que el trabajo con el proceso esquizoide tiene tantas etapas y posibles caminos que es la posición interna de la psicoterapeuta lo que lo hace único y lo hace posible, porque requiere de nuestra profunda introspección y disponibilidad completa para responder a los 
diferentes niveles del tratamiento sin forzar los ritmos ni buscar atajos clínicos, para trabajar con la humildad de renunciar a nuestros objetivos y dejar que sea el descubrimiento de quién es nuestro cliente, qué historia o historias tiene para contar y qué es lo que realmente necesita. Eso es lo que debe guiarnos en todo momento en nuestro trabajo y presencia.

\section{Conclusión}

El proceso esquizoide y sus diversas fases en su formulación desde la Psicoterapia Integrativa requiere por parte del psicoterapeuta una capacidad de estar con y para su cliente de una forma tal que desafíe a sus objetivos clínicos. Nuestro cliente se enfrentará a la paradoja de salir de su refugio al permitirle explorarlo y vivirlo plenamente en nuestra presencia. Esto, sin duda, puede resultar aterrador pero, simultáneamente para el psicoterapeuta se presenta un dilema similar: ha de confiar plenamente en la relación terapéutica, en su valor curativo y en su importancia central porque aquí la tarea no es ayudar a la persona a cambiar sino aceptar plenamente quién es, qué siente, cómo manejó su mundo y descubrir y honrar sus mecanismos de autoprotección. En esto, más que en ningún otro proceso, confiar en la teoría paradójica del cambio (Erskine, 2017a) y saber que si aceptamos al cliente sin invadir ni controlar y si descubrimos la experiencia tal y como es, cliente y psicoterapeuta habrán construido un espacio intersubjetivo, único, seguro y reparador.

Ambos -juntos- tendrán que desafiar su punto de partida y sus certezas para creer en la magia de la relación y la implicación y poder así atravesar todas y cada una de las rupturas internas que van dejando vacíos y van excluyendo aspectos nucleares y vitales de uno mismo; todo ello en un viaje compartido donde la persona podrá reparar poco a poco la relación dañada consigo misma. Esto lo hará a través del vínculo seguro y de la presencia terapéutica implicada y sólida que le presta una mirada y un estar que serán la base del reencuentro con el otro y después, consigo mismo.

\section{Referencias}

Arnheim, R. (1972). Visual thinking [Pensamiento visual]. University of California Press.

Bateson, G. (1976). Pasos hacia una ecología de la mente (R. Alcalde, Trad.). Lohlé. (Trabajo original publicado en 1972)

Berne, E. (1961). Transactional analysis in psychotherapy: a systematic individual and social psychiatry [Análisis transaccional en Psicoterapia: una psiquiatría sistemática individual y social]. Grove Press. https://doi.org/10.1037/11495-000

Berne, E. (1966). Principles of group treatment [Principios de tratamiento grupal]. Grove Press. https://doi.org /10.1080/00207284.1967.11643038

Bion, W. R. (1967). Attention and interpretation: container and contained transformed [Atención e interpretación: contenedor y contenido transformado]. Jason Aronson. https://doi.org/10.4324/9780429472107-12

Bravo, R. (21 de marzo, 2019). Jornada: Claves y retos de las terapias psicológicas en la sociedad actual [ponencia]. Colegio Oficial de Psicología de Bizkaia, Bilbao. https://copbizkaia.org/actualidad/noticia_des. php?id_not=321

Coderch, J. (2016). Teoría y técnica de la psicoterapia psicoanalítica. Herder. (Trabajo original publicado en 1987) 
Cornell, W. F. (2019). At the interface of Transactional Analysis, Psychoanalysis, and Body Psychotherapy: clinical and theoretical perspectives [En la interfaz del análisis transactional, psicoanálisis y psicoterapia corporal: perspectivas clínicas y teóricas]. Routledge. https://doi.org/10.4324/9780429464430

Damasio, A. (2010). Y el cerebro creó al hombre. Ediciones Destino. https://doi.org/10.5093/cc2011v2n2a9

Echeburúa, E. (21 de marzo 2019). Jornada: Claves y retos de las terapias psicológicas en la sociedad actual [Ponencia]. Colegio Oficial de Psicología de Bizkaia, Bilbao. https://copbizkaia.org/actualidad/noticia_des. php?id_not=321

Erskine, R. (20 de agosto, 1999). El proceso esquizoide [Ponencia]. Congreso Anual de la Sociedad Internacional de Análisis Transaccional, San Francisco, Estados Unidos.

Erskine, R. (2010). Life scripts: A Transactional Analysis of unconscious relational patterns [Guión de vida: Un análisis transaccional de los patrones relacionales inconscientes]. Karnac. https://doi. org/10.4324/9780429476686-1

Erskine, R.(2016a). Presencia terapéutica y patrones relacionales. Conceptos y práctica de la Psicoterapia Integrativa (A. Pérez, Trad.). Karnac. https://doi.org/10.4324/9780429203565(Trabajo original publicado en 2015)

Erskine, R. (2016b). Transactional Analysis in contemporary psychotherapy [Análisis transaccional en psicoterapia contemporánea]. Karnac. https://doi.org/10.4324/9780429484179

Erskine, R. (25 de marzo, 2017a). Conferencia de clausura [ponencia]. Asociación Internacional de Psicoterapia Integrativa. Milán, Italia.

Erskine, R. (2017b). Seminario sobre ‘Proceso esquizoide’'[ponencia]. Seminario Psicoterapia Integrativa. Lyon, Francia.

Erskine, R. y Mauriz-Etxabe, A. (2020). Inferencia, re-experimentación y regresión: psicoterapia de los Estados Niño del Yo. Revista de Psicoterapia, 31(116), 205-226. https://doi.org/10.33898/rdp.v31i116.362

Erskine, R., Moursund, J. P. y Trautmann, R. L. (1999). Beyond empathy. Atherapy of contact-in-relationship [Más allá de la empatía. Una terapia de contacto en relación]. Brunner Mazel. https://doi.org/10.4324/9780203778036

Erskine, R. y Moursund, J. (2014). La Psicoterapia Integrativa en acción (I. Arregui, Trad). Desclée de Brouwer. (Trabajo original publicado en 1988)

Erskine, R. y Moursund, J. (2020). Relational withdrawal, attunement to silence: psychotherapy of the schizoid process [Retiro relacional, sintonía con el silencio: psicoterapia del proceso esquizoide] [manuscrito presentado para publicación]. Institute for Integrative Psychotherapy.

Freud, S. (1930). Recordar, repetir, reelaborar (nuevos consejos sobre la técnica del psicoanálisis, II) (L. LópezBallesteros, Trad.). Amorrortu. (Trabajo original publicado en 1914)

García-Monge, J. A. (2017). De la necesidad al deseo. La psicoterapia humanista: “laboratorio”, y experiencia de humanidad. Revista de Psicoterapia, 28(107), 75-84. https://doi.org/10.33898/rdp.v28i107.170

Gimeno-Bayón, A. (2017). Experiencia y existencia en las Psicoterapias Humanistas. Revista de Psicoterapia, 28(107), 207-229. https://doi.org/10.33898/rdp.v28i107.177

Granit, R. (1977). The purposive brain [El cerebro intencional]. The MIT Press.

Guistolise, P. G. (1996). Failures in the therapeutic relationship: inevitable and necessary? [Fallos en la relación terapéutica: ¿inevitable y necesario?]. Transactional Analysis Journal, 26(4), 284-288. https://doi. org/10.1177/036215379602600403

Jaynes, J. (1977). The origin of consciousness in the breakdown of the bicameral mind [El origen de la consciencia en el colapso de la mente bicameral]. Houghton Mifflin.

Kolb, D. A. (1984). Experiential learning: experience as the source of learning and development [Aprendizaje experiencial: la experiencia como fuente de aprendizaje y desarrollo]. Englewood Cliffs.

Lanyado, M. y Horne, A. (1999). Handbook of Child and Adolescent Psychotherapy [Manual de la Psicoterapia y adolescente]. Routledge. https://doi.org/10.1017/s1360641700232498

MacNeil, I. R. (1985). Relational contract: what we do not know [Contrato relacional: qué no sabemos]. Wisconsin Law Review, 4, 483-526.

Masters, R. y Houston, J. (1972). Mindgames: The guide to inner space [Juegos mentales: La guía del espacio interior]. Viking Press.

Mauriz-Etxabe, A. (2004). ¿Qué es efectivo en psicoterapia? Revista Psikologiaz, 6, 10-12.

Mauriz-Etxabe, A. (2016). Los hilos silentes: trabajando con la introyección. Revista de Psicoterapia, 27(105), 59-74. https://doi.org/10.33898/rdp.v27i105.144

McGinley, E. y Varchevker, A. (2013). Enduring trauma through the life cycle [Soportar el trauma a lo largo del ciclo de vida]. Karnac. https://doi.org/10.4324/9780429474262

Miller, E. E. (1975). Selective awareness [Conciencia selectiva]. Autopublicación.

Moreno, J. L. (1974). Psicodrama. Ediciones Hormé. (Trabajo original publicado en 1946) 
Moursund, J. P. y Erskine, R. (2003). Integrative psychotherapy: The art and science of relationship [Psicoterapia integrativa: El arte y la ciencia de la relación]. Thomson.

Nathanson, D. L. (1987). The many faces of shame [Las muchas caras de la vergüenza]. Guilford Press. https:// doi.org/10.1176/ps.39.9.1000

O’Reilly-Knapp, M. (2001). Between two worlds: the encapsulated self [Entre dos mundo: El yo encapsulado]. Transactional Analysis Journal, 31(1), 44-54. https://doi.org/10.1177/036215370103100106

O’Reilly-Knapp, M. (2017). Beyond survival: breaking the code of silence in abuse. A psychotherapist's own journey in the therapy [Más allá de la superviviencia: rompiendo el Código de silencio en abuso. El propio viaje de un psicoterapeuta en la terapia]. Diggy Pod.

Perls, F. (1975). Yo, hambre y agresión. Fondo de Cultura Económica. (Trabajo original publicado en 1942)

Perls, F., Hefferline, R. F. y Goodman, P. (1977). Gestalt Therapy: excitement and growth in the human personality [Terapia Gestalt: excitación y crecimiento de la personalidad humana]. The Gestalt Journal Press.

Siegel, D. (1999). The developing mind [La mente en desarrollo]. Guilford Press. https://doi. org/10.1177/1473325014563215

Steiner, C. (1991). Los guiones que vivimos (M. R. Buixaderas, Trad.). Kairós. (Trabajo original publicado en 1974)

Van der Kolk, B. A., McFarlane, A. y Weisaeth, L. (2007). Traumatic stress: The effects of overwhelming experience on mind, body and society [Estrés traumático: los efectos de una experincia abrumadora en la mente, el cuerpo y la sociedad]. The Guilford Press. https://doi.org/10.1177/00030651980460040502

Rosenfeld, E. (1978). An Oral History of Gestalt Therapy [Una historia oral de la terapia Gestalt]. Gestalt Journal, $1(1), 8-31$.

Yalom, I. D. (2002). El don de la terapia. Carta abierta a una nueva generación de terapeutas y a sus pacientes (J. Salvetti, Trad.). Destino. (Trabajo original publicado en 2001)

\section{Referencias de ilustraciones}

Landa, I. (2020a; 2020b; 2020c; 2020d; 2020e). Ilustraciones [elaboradas expresamente para el presente artículo]. Bilbao: España. 